\title{
A cooperação internacional para o desenvolvimento da Amazônia: a experiência do Programa ARPA
}

The international cooperation for development in the Amazon: ARPA Program's experience

Brenda Thainá Cardoso de Castro - Mestre em Ciência Política pelo Programa de PósGraduação em Ciência Política (PPGCP/UFPA), professora adjunta do curso de graduação em Relações Internacionais da Universidade da Amazônia (UNAMA). E-mail: brendatcc@gmail.com

Alberto Teixeira da Silva - Doutor em Ciências Sociais pela UNICAMP e professor Associado do Instituto de Filosofia e Ciências Humanas da Universidade Federal do Pará (IFCH/UFPA).E-mail: alberts@superig.com.br

\section{Resumo}

A Cooperação Internacional para o Desenvolvimento pressupõe uma relação entre os atores baseada no binômio doadorrecebedor. $O$ presente artigo condensa as principais observações na modificação da relação doador-recebedor nos projetos de cooperação internacional, avaliando a aplicação de conceitos que defendem maior autonomia e participação de atores locais, em detrimento da anterior predominância das diretrizes de atores internacionais. O trabalho está, assim, dividido na apresentação dos conceitos centrais, a visão teórica sobre centro e periferia, as contribuições críticas à Cooperação Internacional e a premissa construtivista da relação agente-estrutura. $\mathrm{Na}$ continuação, apresenta-se o Programa ARPA e analisa-se o mesmo a partir dos conceitos previamente ilustrados por meio de documentos oficiais e entrevistas, concluindo-se que a Cooperação Internacional para o Desenvolvimento tem sofrido modificações e a co-constituição entre agente e estrutura tem tido um papel crucial nestas transformações.

\section{Palavras-chave}

Cooperação Internacional para O Desenvolvimento. Programa ARPA. Coconstituição. Construtivismo.

\begin{abstract}
The International Cooperation for Development implies a donor-recipient relationship between the actors involved. This study approach the modification of the donor-recipient relationship in international cooperation initiatives, evaluating the application of concepts that advocate more autonomy and participation of local actors, rather than the previous dominance of the guidelines by international actors. It's initially presented the central concepts, theoretical view of the center-periphery idea, the critical contributions to international cooperation and the constructivist premise of the agentstructure relationship. The following shows the ARPA Program and it is analyzed from the concepts previously presented using official documents and interviews. It concludes that the International Cooperation for Development has been modified and the co-constitution between agent and structure has played a crucial role in these transformations.
\end{abstract}

\section{Keywords}

International

Cooperation

for Development. ARPA Program. Coconstitution. Constructivism. 


\section{INTRODUÇÃO}

Tradicionalmente, a dinâmica dos atores na cooperação internacional para o Desenvolvimento tem como premissa a assimétrica relação entre os países desenvolvidos e em desenvolvimento; onde se espera que os primeiros sejam os provedores de recursos financeiros e técnicos e que os segundos sejam recipientes destes, assim como de suas políticas e diretrizes.

Partindo da ponderação acerca da relação doador-recebedor como tradicional e, para alguns, imutável, o presente estudo visou a análise da cooperação internacional com enfoque ambiental, pelo Programa ARPA, para viabilizar a discussão aqui proposta ${ }^{1}$.

Para tanto, partir-se-á de uma elaboração teórica sobre visões das Relações Internacionais (RI) para com este fenômeno, desde os mais clássicos como a corrente realista e idealista, passando por contribuições críticas e periféricas como a Teoria da Dependência e a Teoria da Autonomia, seguindo para discussões mais atuais como a Teoria Construtivista.

A seguir, serão explanados os conceitos propostos por entidades internacionais frente à operacionalização da cooperação internacional para o desenvolvimento no final do século XX, com ênfase nas publicações patrocinadas pela OCDE, pelo PNUD e pelo Banco Mundial.

Então, o Programa ARPA será apresentado com seus objetivos, resultados e características peculiares, visando à verificação da aplicação dos conceitos previamente definidos como indispensáveis para uma cooperação mais eficaz.

Por fim, discutir-se-ão os resultados observados e os principais temas e questionamentos que emergiram na presente pesquisa.

\section{TEORIZAR A COOPERAÇÃO INTERNACIONAL PARA O DESENVOLVIMENTO}

Os motivos que levam os atores a cooperarem já foram discutidos por diversos pensadores das RI (WENDT, 1999; KEOHANE, 1984; STEIN, 1990, entre outros), mesmo quando o assunto não era o objetivo, a cooperação é tema recorrente para discutir a guerra, a paz, a interdependência econômica e o direito internacional.

1 Este trabalho é a culminância das pesquisas realizadas para a elaboração da dissertação de Mestrado em Ciência Política, defendida em agosto de 2015 no Programa de Pós-Graduação em Ciência Política da Universidade Federal do Pará (PPGCP/UFPA), cujo título foi "Dinâmica de atores na Cooperação Internacional para o Desenvolvimento: o Programa Áreas Protegidas da Amazônia”. 
Falar sobre a cooperação internacional para o desenvolvimento é uma escolha que decide se afastar dos outros tipos de cooperação internacional. Aquelas que podem dizer respeito a qualquer ato, acordo ou alinhamento de políticas e interesses entre dois ou mais Estados, assim como com outros atores internacionais.

As teorias mais clássicas das RI tinham como ponto de discussão a cooperação ora encarando-a com ceticismo (realismo/neorrealismo) ora como ferramenta indissociável do progresso rumo à paz (idealismo/neoidealismo) (NOGUEIRA; MESSARI, 2005).

A cooperação internacional para o desenvolvimento - ou CID - diz respeito às iniciativas voltadas para a articulação entre países desenvolvidos e subdesenvolvidos ou em desenvolvimento em via de promover a melhoria econômica e social dos países que necessitam. Segundo Milani (2012, p. 211)

A cooperação internacional para o desenvolvimento (CID) pode ser definida como um sistema que articula a política dos Estados e atores não governamentais, um conjunto de normas difundidas (ou, em alguns casos, prescritas) por organizações internacionais e a crença de que a promoção do desenvolvimento em bases solidárias seria uma solução desejável para as contradições e as desigualdades geradas pelo capitalismo no plano internacional.

Pode-se afirmar, destarte, que ao falarmos de CID, não se trata apenas de uma ajuda - técnica ou financeira - mas um ato que transporta valores de um caminho a ser seguido. A lógica de que uma parte do mundo chegou ao progresso, ao seu destino - o significado de desenvolvimento propõe um caminho para alcançar um estágio final - e que agora ajudará os demais a trilharem o mesmo percurso.

No âmbito teórico, destacam-se alguns trabalhos que criticam a relação centro-periferia, na América do Sul, em especial, os voltados para a Teoria Crítica tais como: a Teoria da Dependência ${ }^{2}$, difundida a partir da década de 1960 por André Gunder Frank, Ruy Mauro Marini, Vania Bambirra e Theotonio dos Santos, entre outros; e a Teoria da Autonomia³, nos anos 1970 e 1980 pela exposição de Hélio Jaguaribe, Juan Carlos Puig e Miryam Colacrai.

2 A Teoria da Dependência critica a Teoria do Desenvolvimento proposta por Raúl Prebisch (1954), o qual tinha uma proposta para diretrizes nos países subdesenvolvidos para alcançarem o desenvolvimento. A crítica é feita no tom de que desenvolvimento e subdesenvolvimento são aspectos de um mesmo processo, e não um estágio necessário para chegar ao outro. Assim sendo, discute-se o subdesenvolvimento como consequência e que a cooperação internacional atuaria como ferramenta para manutenção do status quo (BLONSTROM; HETTNE, 1984 apud DOS SANTOS,2000).

3 A Teoria da Autonomia vai partir também da divisão do mundo entre centro e periferia, mas considera a mobilidade de um país do nível de dependência para o de autonomia e discutirá os fatores e características presentes em quatro níveis (primazia geral, primazia regional, autonomia e dependência) (JAGUARIBE, 1979). 
Assim, tem-se um panorama de uma variedade de interpretações do que a cooperação internacional pode significar. Indo muito além da crença no altruísmo, mas também não se acomodando na ideia de um fenômeno utópico e inviável. O que as teorias descritas acima abordaram sobre as críticas ao fenômeno da cooperação internacional por muito tempo estagnou-se na academia.

Como perceberemos adiante, as contribuições que remodelarão a ideia da CID virão não da teoria, mas da práxis.

\subsection{NOVOS CONCEITOS PARA UMA VELHA DINÂMICA}

Do ponto de vista do funcionamento da cooperação internacional as principais contribuições recentes estão em relatórios de organizações internacionais publicados em meados da década de 1990.

Nos anos 1950 e 1960, a cooperação técnica foi formulada como um mecanismo de execução para transferência de tecnologia e aptidões humanas para países tomadores de empréstimos. [...] Nos anos 1970 e 1980 foi redefinida para dedicar maior atenção a consequências sustentáveis por meio de novas práticas inerentes a organizações formais que iriam durar até depois do fim da assistência. Em meados dos anos 1990, houve uma mudança convencional no propósito e metodologia da cooperação técnica. Ela passou a ser vista não como uma transferência, mas como processo mais amplo formulado para criar e disseminar conhecimento humano com resultados esperados de desenvolvimento em todos os níveis da sociedade. [...] Inclui tanto concessões a pessoas de países receptores em termos de educação ou treinamento em seu país de origem ou no exterior, quanto pagamentos a consultores, professores e administradores que prestam serviços nos países receptores” (LOPES, 2005, p. 178).

Lopes (2005) aponta na citação acima o contexto no qual as críticas à metodologia da cooperação internacional - com ênfase na técnica - sofrerá. Neste período, serão publicados relatórios que tentarão redirecionar a CID visando uma maior eficácia (evitando gastos e alcançando objetivos), sendo estes: DAC Principles for effective Aid (OCDE, 1992), Rethinking Technical Cooperation: reforms for capacity building in Africa (BERG, 1993) e Assessing Aid: what works, what doesn't and why (DOLLAR; PRITCHETT, 1998).

Estes relatórios contribuirão com a proposta de conceitos (Quadro 1) que deveriam ser considerados no momento da implantação de políticas e projetos de cooperação internacional, tais como: apropriação, empoderamento (empowerment), desenvolvimento de capacidades (capacity development), participação, mútua responsabilidade e origem da iniciativa (LOPES, 2005).

Novos Cadernos NAEA •v. 20 n. $2 \cdot$ p. 149-164 • maio-ago 2017 


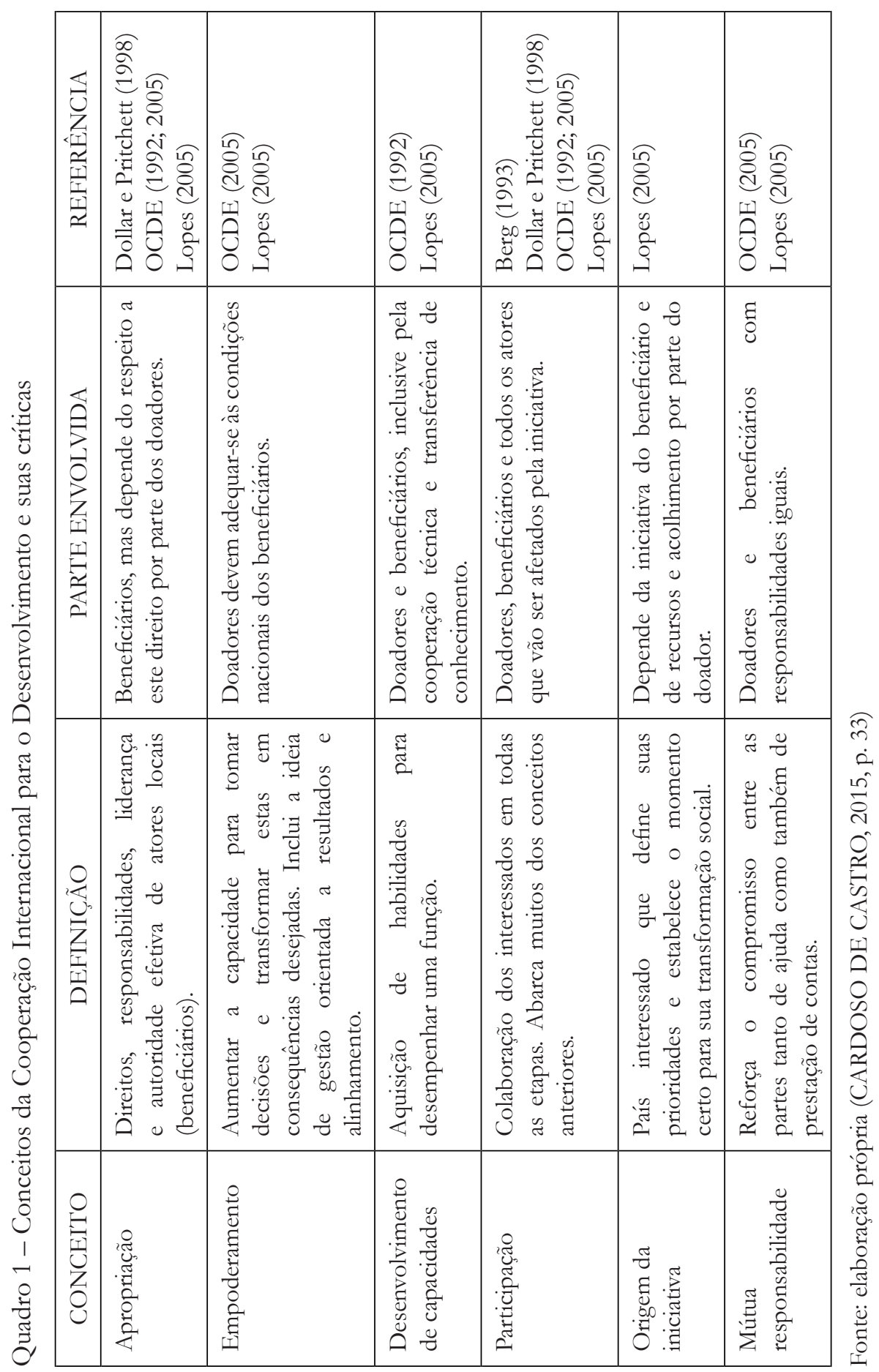

Novos Cadernos NAEA • v. 20 n. 2 • p. 149-164 • maio-ago 2017 
Isto posto, pode-se notar um questionamento da dinâmica entre os atores na CID, a tradicional relação doador-beneficiário que denotava um processo respectivamente ativo-passivo não mais é o suficiente para garantir a eficácia da cooperação.

Notou-se que ao não envolver os atores locais e permitir que os mesmos tenham igual função nos projetos, a chance dos resultados culminarem em desperdício de tempo e dinheiro é maior.

Lopes (2005) adiciona ainda à questão que não basta apenas a participação e o envolvimento local num projeto se este tem o seu conteúdo, objetivo, diretrizes e momento para transformação social definidos por um ente exógeno à realidade da localidade. Ressalta ainda, que dificilmente a ajuda será recusada, mas isso não significa que ela será implementada da melhor forma possível.

Ainda que estas proposições tenham partido de organizações envolvidas no processo da CID, o que nos leva a afirmar uma contribuição da práxis, não da academia, pode-se perceber a predominância da premissa construtivista nos conceitos e na crítica.

\subsection{UMA ABORDAGEM CONSTRUTIVISTA PARA A CID}

Ao utilizar conceitos que tratam da construção de uma relação, pontuando as falhas de experiências anteriores por falta de maior envolvimento - e até mesmo de espaço - para que atores locais se envolvessem, infere-se uma dinâmica de mutabilidade das relações sociais. Esta premissa tem como suporte teórico a Teoria Construtivista, segundo a qual:

Vivemos em um mundo que construímos, no qual somos os principais protagonistas, e que é produto das nossas escolhas. Este mundo em permanente construção é construído pelo que os construtivistas chamam de agentes. Vale dizer: não se trata de um mundo que nos é imposto, que é predeterminado, e que não podemos modificar. Podemos mudálo, transformá-lo, ainda que dentro de certos limites. Em outras palavras, o mundo é socialmente construído (NOGUEIRA; MESSARI, 2005, p. $160)$.

Entretanto, a visão construtivista não é tão aceita como uma teoria per se das Relações Internacionais (ONUF, 1998). Nogueira e Messari (2005, p. 165166) refletem sobre a dificuldade de reconhecimento que o construtivismo sofreu na área, justamente por alguns autores a definirem como metateoria, quase uma filosofia, do que propriamente uma teoria que cria ferramentas para estudar os fenômenos das relações internacionais. 
Nas últimas décadas a via construtivista começou a se desenvolver cada vez mais buscando superar estas dificuldades. O interessante para o debate aqui proposto é que os autores que trabalham esta abordagem começam a focar nas normas e regras - o que já tinha sido feito por outras teorias como a Escola Inglesa -, mas com influências, claro, da concepção construtivista (ibidem, p. 169-170).

Onuf (1998, p. 59), por exemplo, define como regras aquilo que diz o que devemos fazer, sendo o "o que" um padrão de conduta a ser seguido em determinadas situações similares e o "devemos" diz para nos adequarmos a este padrão.

A constructivist approach to co-constitution, by contrast, suggests that the actions of states contribute to making the institutions and norms of international life, and these institutions and norms contribute to defining, socializing, and influencig states. Both the institutions and the actos can be redefined in the process (HURD, 2008, p. 304).

Logo, a abordagem construtivista revela a realidade apresentada na concepção da co-constituição entre agente-estrutura, possibilitando não apenas a mutabilidade das relações, mas abrindo espaço para uma análise mais profunda do estudo das relações entre os agentes e as normas nas relações internacionais.

A pesquisa realizada visou a identificação e discussão dos conceitos oriundos relatórios da década de 1990 com base na premissa construtivista na implementação do Programa Áreas Protegidas da Amazônia, o Programa ARPA.

\section{A EXPERIÊNCIA DO PROGRAMA ARPA}

O Programa Áreas Protegidas da Amazônia (ARPA) foi lançado em 2002 pelo Governo Federal pelo Decreto no 4.326 , no qual era previsto para duração de 13 anos, divididos em três fases, atualmente, encontrando-se na terceira. Contudo, no ano de 2014 foi aprovada a criação do Fundo de Transição e a extensão do programa por mais 25 anos, conforme dispõe a Ata da Reunião do Comitê do Programa Arpa, de 15 de dezembro de 2014, realizada em Brasília/DF.

Apesar de anunciada como uma iniciativa do Governo Federal do então presidente Fernando Henrique Cardoso durante a Conferência Rio+10 em Johanesburgo, na África do Sul, o ARPA surge da aliança entre a Rede World Wide Fund for Nature (WWF) e o Banco Mundial em 1998 (WORLD BANK; WWF, 2005) em prol da conservação florestal e uso sustentável.

O Programa ARPA será inserido também no seio do Programa Piloto para Proteção das Florestas Tropicais do Brasil (PPG7), compondo o quadro 
de doadores do Programa ARPA principalmente o Banco Mundial (pelo Global Enviromental Facility (GEF)), a Rede WWF (Internacional e a WWF Brasil), e a Alemanha (pelo Banco de Desenvolvimento da Alemanha (KfW)).

O programa é reconhecido internacionalmente como "o maior programa de conservação e uso sustentável de florestas tropicais do mundo" (MANUAL OPERACIONAL ARPA, 2013, p. 7) pelos êxitos obtidos não apenas em atingir as metas estipuladas, mas por superá-las ${ }^{4}$.

O escopo da iniciativa é a criação de Unidades de Conservação (UC) na Amazônia brasileira, mas tem também como contribuição ferramentas que visavam o caráter de subsistência da iniciativa, mesmo após o fim da ajuda internacional.

Destas, pode-se destacar: a) a criação do Fundo Áreas Protegidas; b) um organograma que busca envolver e possibilitar o espaço para todos os atores interessados na temática (no âmbito do governo, doadores e atores locais); c) uma adaptação flexível à realidade local em procedimentos definidos pelos doadores.

O Fundo Áreas Protegidas (FAP) sofreu uma modificação para o Fundo de Transição - com a previsão dos 25 anos para a independência do programa. O montante que já havia sido criado com intuito de garantir a sobrevivência do projeto após sua conclusão agora contará também com uma diminuição gradativa do financiamento internacional, passando para a contrapartida governamental.

$\mathrm{O}$ arranjo institucional do ARPA é interessante, pois representa bem o caráter transitório da CID - da relação ativo-passiva de doador-beneficiário para maior envolvimento e participação dos atores locais (Figura 1).

O Comitê do Programa ARPA, por exemplo, é composto por representantes da esfera pública (Ministério do Meio Ambiente, Instituto Chico Mendes de Conservação da Biodiversidade e outros), da esfera privada (doadores), da sociedade civil organizada (Fundo Brasileiro para a Biodiversidade, WWF, Grupo de Trabalho Amazônico e outras ONG locais).

Apesar da divisão do arranjo institucional indicar a execução como encargo da esfera pública e o financiamento como da esfera privada, na prática, os órgãos descritos são compostos por membros de ambas as esferas 5 .

4 A Fase I (2003-2010) superou em 20\% as metas de criação de 9 milhões de hectares de Unidades de Conservação em áreas de uso sustentável e mais $20 \%$ nas áreas de proteção integral. No âmbito da capitalização para estabelecer um fundo fiduciário a meta foi superada em $77 \%$, resultando no Fundo Áreas Protegidas (FAP) com a capitalização de US\$24,8 milhões. Os dados atuais revelam que o Programa já atingiu a criação e proteção de mais de 60 milhões de hectares. (PROGRAMA ARPA. Fase I. Disponível em: < http://programaarpa.gov.br/ uncategorized/fasei/>. Acesso em: 25 jan. 2015).

5 O modelo representa uma complexa dinâmica na CID: o Ministério do Meio Ambiente e o Comitê (que reúne todos os parceiros e envolvidos de forma paritária) como instância máxima e deliberativa; a instância consultiva formada pelo Painel Científico de Aconselhamento e o 
Figura 1 - Arranjo institucional do Programa ARPA

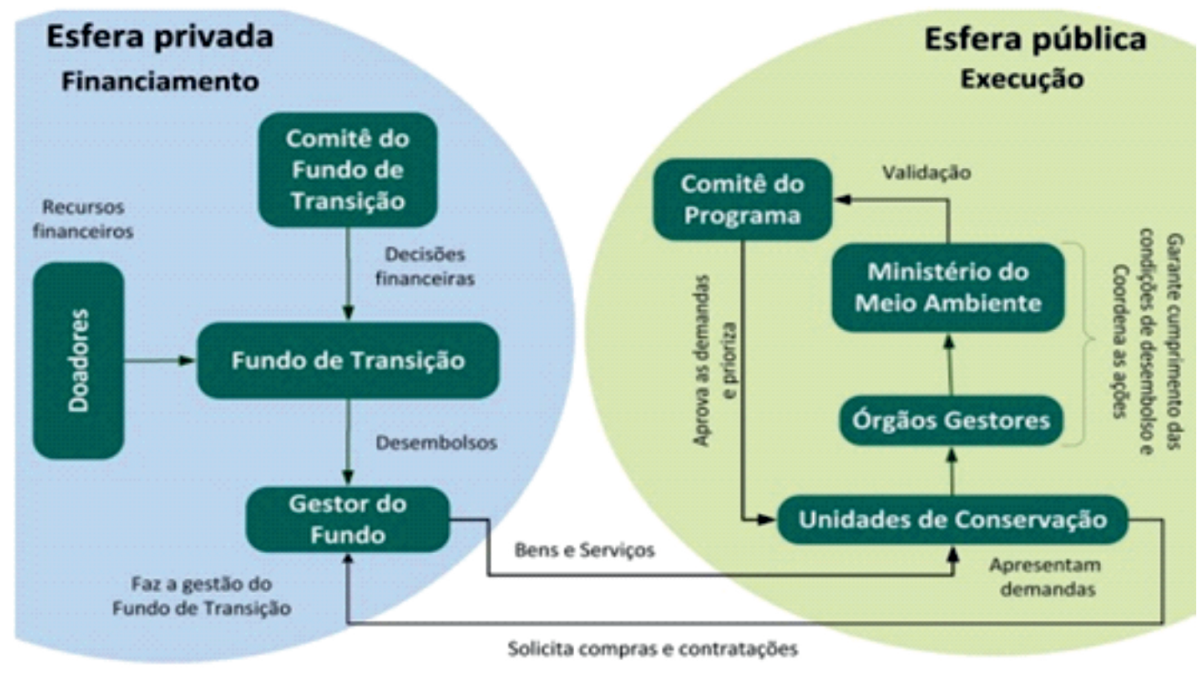

Fonte: Manual Operacional ARPA (2013)

Sobre a adaptabilidade percebida na implementação do programa, observase a criação da ferramenta da conta vinculada, uma estratégia que permite a flexibilidade dos pontos focais (órgãos gestores das UC, coordenados pelo ICMBio) para lidarem com a realidade amazônica que às vezes não corresponde aos requisitos estabelecidos pelos doadores (como a emissão de nota fiscal, licença e até mesmo opções de serviços para licitação).

No tocante à identificação dos conceitos para a melhor eficácia da CID, a pesquisa alcançou seu objetivo, notando a aplicação de todos (Quadro 2).

Fórum Técnico (UCP, Funbio e a Cooperação Técnica (WWF-Brasil e GIZ); a coordenação pela Secretaria de Biodiversidade e Florestas (SBF) e a Unidade do Comitê do Programa (UCP); a execução técnica a cargo dos órgãos gestores das UC; e, a execução financeira a cargo do Funbio (MANUAL OPERACIONAL ARPA, 2013). 


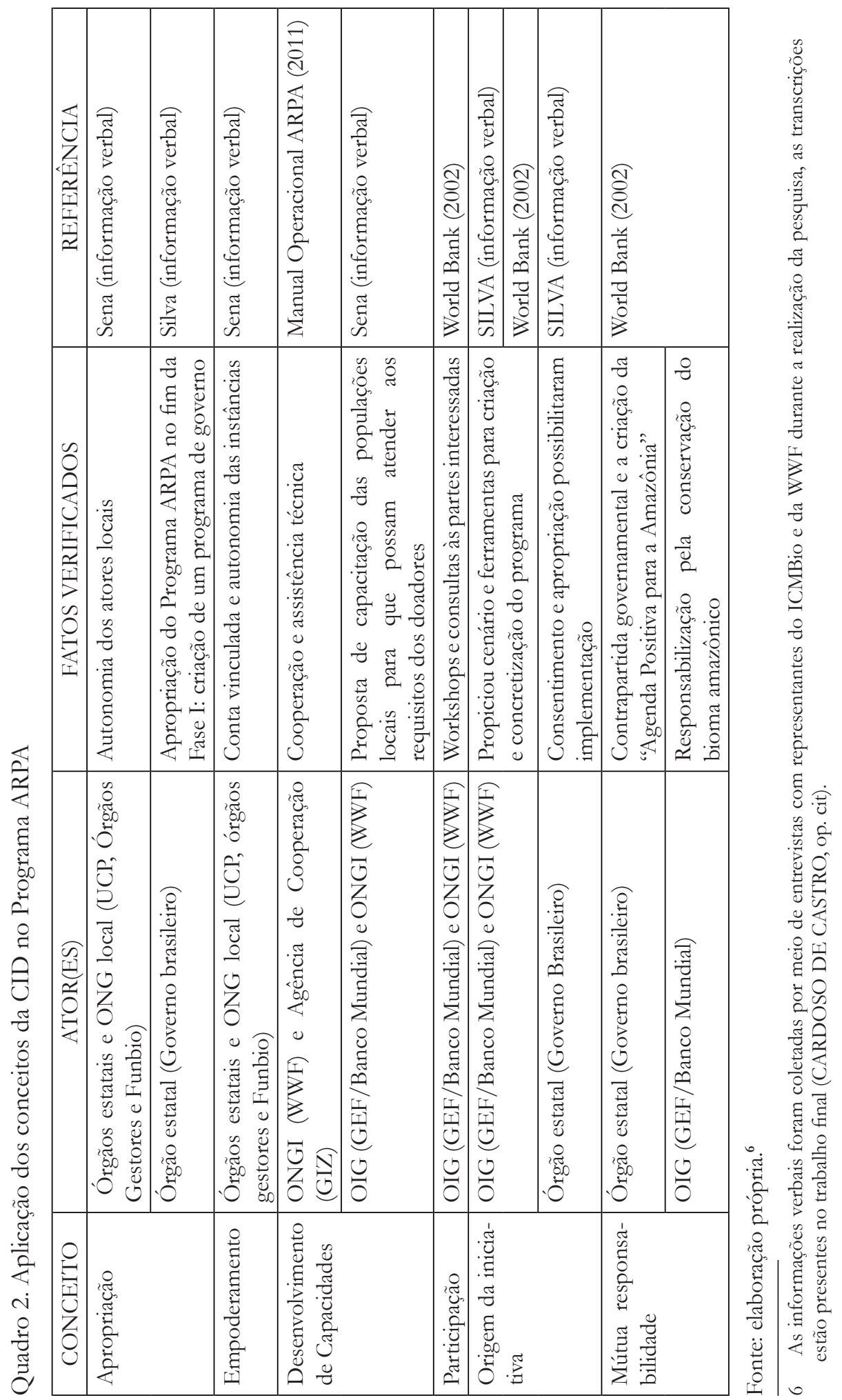


E mais, percebe-se também a complexidade da relação doador-beneficiário no atual contexto. Sendo financiadores do programa tanto os atores internacionais quanto o próprio governo com a contrapartida governamental.

Dos aproximadamente US\$ 171 milhões aportados nas duas fases do programa: pouco mais de 60\% são oriundos de fontes de financiamento internacional; 31\% da contrapartida governamental e 9\% de outros (Fundo Amazônia e menores doações como da Natura e O Boticário, as demais ONG que têm contribuído para a Iniciativa Arpa para a Vida ainda não foram inseridas nos relatórios financeiros) (PROGRAMA ARPA, 2015).

Logo, a experiência do Programa ARPA comprovou não apenas uma nova tendência no âmbito da dinâmica da CID, como também revelou o enredamento das relações entre os atores envolvidos.

No tocante ao conceito da origem de iniciativa (LOPES, 2005), a questão ainda é dúbia, pois o caso do ARPA remete a uma proposta idealizada e projetada pela WWF e o GEF, mas também contou com a contribuição do Governo Federal, principalmente no momento das modificações da proposta inicial que dizia respeito somente a benefícios para área de conservação integral e após consultas e negociações ampliaram-se para as áreas de uso sustentável também, por ser uma realidade muito característica da Amazônia.

\section{UMA NOVA DINÂMICA ENTRE OS ATORES NA COOPERAÇÃO INTERNACIONAL PARA O DESENVOLVIMENTO}

Os temas que foram observados na condução da pesquisa levaram a algumas considerações e também a questionamentos, os quais podem ser decompostos em: a) a relação teoria-práxis; b) a nova dinâmica da cooperação internacional; e, c) que desenvolvimento para a Amazônia.

A primeira discussão concerne justamente ao distanciamento aparente entre as teorias das relações internacionais e a realidade, entre subjetividades e dogmas, o cenário internacional segue cada vez mais complexo e em muitos casos o seu estudo nos leva apenas a uma certeza: da incapacidade de oferecerlhe respostas.

O crescimento da Teoria Construtivista - que mais se apresenta como metateoria - tem sua explicação nesse fenômeno, já que não limita muito a compreensão do mundo, mas também fornece poucas ferramentas aos estudiosos.

Cervo (2008) argui que a tendência da área talvez esteja mais voltada para a discussão de conceitos que apegos a dogmas teóricos ou debates rivalizados. Isto se exemplifica nos resultados expostos, haja vista que a práxis (produções 
no âmbito das organizações promotoras da cooperação internacional) tem feito colaborações que visam - e tem demonstrado mudanças na dinâmica destas relações - a superação de obstáculos.

Logo, percebendo-se a necessidade de uma renovação teórica mais próxima à prática e menos apegada a ideais e modelos, mas voltada para desafios reais e passíveis de solução.

O segundo tema trata também de outra tendência nas relações internacionais: a governança.

Young (1994, p. 15, apud SILVA, 2015, p. 110) discute a governança do ponto de vista da "criação e funcionamento de instituições, sociais", destacando a ideia de "regras de jogo", as quais têm como função "definir práticas sociais, designar papeis e orientar as interações entre os que os desempenham". E é, neste ponto, que nossa discussão se desenvolve.

Quando esta governança possibilita, a partir de regras (conforme previamente abordado no viés construtivista) o funcionamento de instituições com apoio de múltiplos atores interessados e afetados pelo tema em questão, visualiza-se exatamente o cenário aqui construído.

A questão ambiental mostra-se como um tema ainda mais relevante, pois remonta às responsabilidades compartilhadas e o seu caráter transfronteiriço. Consequentemente, temos uma readaptação dos atores, na qual a dinâmica do sistema internacional também necessita se reformular, criando novos mecanismos de reconhecimento e participação destes.

A governança tem sido, deste modo, a nova dinâmica que tem ditado as relações na CID, seja pelo discurso das organizações internacionais intergovernamentais pelos conceitos que repensam esta, ou até mesmo pela pressão exercida pela sociedade civil organizada para ser reconhecida como ator legítimo que representa os anseios das populações.

Por fim, tem-se em mente a grande questão: mas que desenvolvimento seria este que a CID almeja? Seria ele viável e legítimo?

As reflexões críticas à ideia de desenvolvimento não são poucas (FURTADO, 1974; LOPES, 2005; SEN, 2010; KRAYCHETE, 2012), mas todas têm em comum o questionamento sobre os padrões que são utilizados para medir tanto o progresso de países com histórias e necessidades diferentes, como para ponderar a viabilidade de um dia todos os países do mundo alcançarem estes objetivos.

Isto permeia sobre as diretrizes de políticas que visam o desenvolvimento, as quais, dependendo do ator em foco pode significar crescimento econômico, a exploração de recursos naturais, a preservação ou conservação do ecossistema, a garantia dos direitos humanos fundamentais, entre outros. 
Esta rede emaranhada de significados do desenvolvimento na Amazônia tem resultado recentemente em conflitos entre as políticas nacionais para a região e o descontentamento de muitos atores que serão atingidos por estas, como os casos dos empreendimentos de usinas hidrelétricas (Belo Monte e Tapajós).

Exemplos como estes nos levam a ponderar da necessidade de repensar não apenas a cooperação internacional e a sua dinâmica entre doador-beneficiário, mas também como inspiração para rever as ferramentas de representatividade e participação dentro da própria soberania.

\section{CONSIDERAÇÕES FINAIS}

Paradoxalmente, a cooperação internacional tem sido ao mesmo tempo onipresente nas relações internacionais e relegada. Discute-se a cooperação muito mais como um fim ou um fenômeno, da sua viabilidade ou perenidade, mas pouco se observa nas contribuições teóricas discussões contundentes para a implementação, dos desafios e operacionalidade da mesma.

A CID, por ter avançado consideravelmente no contexto pós Segunda Guerra Mundial, forneceu uma experiência que permitiu no fim do século passado um balanço sobre os desafios que viriam na cooperação após a superação do ceticismo que esta envolvia.

Os relatórios e os conceitos propostos pela OCDE, Banco Mundial e PNUD parecem ter redirecionado as práticas da cooperação, motivados não por um altruísmo utópico, mas por resultados melhores e um maior aproveitamento dos recursos destinados a estes programas.

O Programa ARPA permitiu a verificabilidade da aplicação de conceitos caros à CID como empoderamento, participação, apropriação, mútua responsabilidade, desenvolvimento de capacidades e origem da iniciativa, confirmando a tendência da transformação do paradigma doador-recebedor.

Mais do que uma transformação de fato, pode-se dizer que foi observada uma transição, ao notarmos a mescla das funções desempenhadas pelos atores internacionais e locais, não mais ficando a cargo dos internacionais - como era tradicionalmente - o financiamento, ocorrendo também a contrapartida significativa e que o programa demonstrou a intenção de sobreviver sem o financiamento externo.

A questão ambiental é imprescindível para a discussão sobre a concepção de desenvolvimento, pois nos permite aliar todas as esferas (social, econômica, ambiental e política) e ponderar sobre os caminhos que estamos seguindo. 
E se falando de Amazônia, o desafio vai além das lições de cooperação e mútua responsabilidade, paira ainda sobre onde se pretende chegar, se o horizonte que se mira é real ou uma miragem.

\section{REFERÊNCIAS}

BERG, E. Rethinking Technical Cooperation: reforms for capacity building in Africa. New York: UNDP, 1993. Disponível em: <http://capacity.undp.org/ berg/1stpage.pdf>. Acesso em: 04 set. 2014.

CARDOSO DECASTRO, B. T.Dinâmica dos atores na Cooperação Internacional para o Desenvolvimento: o Programa Áreas Protegidas da Amazônia (ARPA). 2015. 100f. Dissertação (Mestrado em Ciência Política) - Instituto de Filosofia e Ciências Humanas, Universidade Federal do Pará, Belém, 2015.

CERVO, Amado Luiz. Conceitos em Relações Internacionais. Revista Brasileira de Política Internacional, v. 51, n. 2, p. 8-25, 2008.

DOLLAR, D. PRITCHETT, L. Assessing aid - what works, what doesn't, and why. Washington D.C.: The World Bank, 1998. Disponível em: http:// documents.worldbank.org/curated/en/1998/11/438890/assessing-aid-worksdoesnt. Acesso em: 04 set. 2014.

FURTADO, Celso. O mito do desenvolvimento econômico. Rio de Janeiro: Paz e Terra, 1974.

JAGUARIBE, H. Autonomia periférica y hegemonía céntrica. Revista Estudios Internacionales, v. 12, n. 46, p. 91-130, 1979.

HURD, I. Constructivism. In: REUS-SMIT, C; SNIDAL, D. The Oxford Handbook of International Relations. Oxford: Oxford University Press, 2008. p. 298-316.

KEOHANE, R. After hegemony: cooperation and discord in the world political economy. New Jersey: Princeton University Press, 1984.

KRAYCHETE, Elsa Sousa. Desenvolvimento e cooperação internacional. Caderno CRH, Salvador, v. 25, n. 65, p.183-186, 2012.

LOPES, C. Cooperação e desenvolvimento humano: a agenda emergente para o novo milênio. São Paulo: Ed. UNESP, 2005.

MILANI, C. R. S. Aprendendo com a história: críticas à experiência da Cooperação Norte-Sul e atuais desafios à Cooperação Sul-Sul. Caderno CRH, Salvador, v. 25, n. 65, p. 211-231, 2012. 
NOGUEIRA, J. P. MESSARI, N. Teoria das Relações Internacionais: correntes e debates. Rio de Janeiro: Ed. Campus, 2005.

OCDE. Declaração de Paris sobre a Eficácia da Ajuda ao Desenvolvimento. Paris, 2005. Disponível em: http://www.oecd.org/dac/effectiveness/38604403. pdf. Acesso em: 05 jan. 2015.

DAC Principles for effective aid. Paris, 1992.

ONUF, N. Constructivism: a user's manual. In: KUBALKOVA, V.; ONUF, N.; KOWERT, P. International relations in a constructed world. New York, 1998.

PREBISCH, R. La Cooperación Internacional en la Política de Desarrollo Latinoamericana. New York: Nações Unidas, 1954.

PROGRAMA ARPA. Contrapartida Governamental por Órgão Gestor ao Programa ARPA - Fase II. Disponível em: <http://programaarpa.gov.br/wpcontent/uploads/2012/09/Contrapartidas_OG_ano.pdf>. Acesso em: 18 maio 2015.

Doadores e Cooperação Técnica. Disponível em: <http:// programaarpa.gov.br/uncategorized/doadores-e-cooperacao-tecnica/>. Acesso em: 18 maio 2015.

Fase I. Disponível em: <http://programaarpa.gov.br/uncategorized/ fasei/>. Acesso em: 25 jan. 2015

Fase II. Disponível em: <http://programaarpa.gov.br/uncategorized/ fase-ii/>. Acesso em: 25 jan. 2015.

Manual Operacional do Programa ARPA. Brasília: MMA, 2013. Disponível em: http://programaarpa.gov.br/wp-content/uploads/2014/10/ Novo_MOP_ARPA_faseIII.pdf. Acesso em: 30 jan. 2015.

Manual Operacional - Fase II 2010/2015. Brasília: MMA, 2011. Disponível em: <http://www.programaarpa.gov.br/wp-content/ uploads/2012/10/mop_arpa_16jan2012.pdf>. Acesso em: 25 jan. 2015.

Relatório para Comprovação da Contrapartida do Governo Brasileiro na Primeira Fase do Programa ARPA (2004-2008). Brasília: MMA, 2009. Disponível em: <http://www.programaarpa.gov.br/wpcontent/uploads/2012/10/relatrio_ contrapartida_governamental_-_arpa_fase_i.pdf>. Acesso em: 18 maio 2015.

Programa Áreas Protegidas da Amazônia: um novo caminho para a conservação da Amazônia. Disponível em: <http://www.programaarpa.gov.br/ 
wp-content/uploads/2012/10/livreto-arpa-portugues.pdf $>$. Acesso em: 20 set. 2014.

SEN, Amartya. Desenvolvimento como liberdade. Trad. Laura Teixeira Motta. São Paulo: Companhia das Letras, 2010.

STEIN, A. A. Why Nations Cooperate: circumstance and choice in International Relations. Ithaca: Cornell University Press, 1990.

WENDT, A. Social Theory of International Politics. Cambridge: Cambridge University Press, 1999. 